\title{
Letter to the editor: Microsurgical decompression for central lumbar spinal stenosis: a single-center observational study
}

\author{
Lorenzo Nigro $^{1} \cdot$ Pasquale Donnarumma ${ }^{1}$
}

Received: 10 August 2016 / Accepted: 7 September 2016 / Published online: 20 September 2016

(C) Springer-Verlag Wien 2016

\section{Dear Editor,}

We read with great interest the article by Giannadakis et al., Microsurgical decompression as treatment for central lumbar spinal stenosis [Giannadakis C, Hammersboen LE, Feyling C et al. (2015);157(7):1165-71] [2]. They reported an interesting single-center observational study in which the surgical results of microsurgical decompression were evaluated through data collected at the Norwegian Registry for Spine Surgery (NORspine) from 2007-2012. Demographics and lifestyle issues in addition to primary and secondary outcome measures were assessed using preoperative and postal follow-up questionnaires.

We would like to point out just one observation.

Giannadakis et al. reported the use of microsurgical decompression in a series of patients. Compared to laminectomy, microsurgical decompression is a less invasive procedure in which, via a smaller incision, the decompression of the dural sac and nerve roots is obtained. In microsurgical decompression the spinous processes and supra- and interspinous ligaments are left intact. In their study only patients without radiological instability were included but how the instability was preoperatively assessed was not reported. We consider the flexion/extension radiograph a useful examination in the assessment of lumbar instability, and we recently reported that instability is sometimes not evident at static examinations and the dynamic examination can reveal it. In these cases it is called microinstability [3]. Microinstability has clinical relevance and may be helpful to distinguish patients who require decompression alone from those who require decompression

Lorenzo Nigro

nigro86@hotmail.it

1 Department of Neurology and Psychiatry "Sapienza" University of Rome, viale del Policlinico, Rome, Italy plus fixation [1]. Giannadakis et al. reported low complication rates in microsurgical decompression for central lumbar stenosis in patients without radiological instability; however, an equivalent outcome was previously demonstrated in microsurgical decompression or laminectomy [4]. It would be interesting to assess microsurgical decompression in patients affected by microinstability, since in these patients a standard laminectomy may aggravate the instability, and fixation is probably too aggressive a treatment. Unfortunately, a prospective study in microsurgical decompression for patients affected by radiological microinstability is missing.

\section{Compliance with ethical standards}

Conflict of interest The authors report no conflict of interest and no study funding.

\section{References}

1. Donnarumma P, Tarantino R, Nigro L, Rullo M, Messina D, Diacinti D, Delfini R (2016) Decompression versus decompression and fusion for degenerative lumbar stenosis: analysis of the factors influencing the outcome of back pain and disability. J Spine Surg 2(1):52-58

2. Giannadakis C, Hammersbøen LE, Feyling C, Solheim O, Jakola AS, Nerland US, Nygaard ØP, Solberg TK, Gulati S (2015) Microsurgical decompression for central lumbar spinal stenosis: a single-center observational study. Acta Neurochir (Wien) 157(7):1165-71

3. Landi A, Gregori F, Mancarella C, Maiola V, Maccari E, Marotta N, Delfini R (2015) Lumbar spinal degenerative "microinstability": hype or hope? Proposal of a new classification to detect it and to assess surgical treatment. Eur Spine J 24(Suppl 7):872-8

4. Nerland US, Jakola AS, Solheim O, Weber C, Rao V, Lønne G, Solberg TK, Salvesen Ø, Carlsen SM, Nygaard ØP, Gulati S (2015) Minimally invasive decompression versus open laminectomy for central stenosis of the lumbar spine: pragmatic comparative effectiveness study. BMJ 350:h1603 